\title{
Molecular Biology for HPV Typing in Focal Epithelial Hyperplasia
}

To the Editor,

Parichehr Ghalayani and colleagues (Volume 31, Number 1, Pages:060-063) report three interesting cases of focal epithelial hyperplasia (FEH) diagnosed through clinical and microscopic analysis (1). We would like to emphasize that, although the age and ethnicity of the patient may support the clinical suspicion of FEH, the histopathological features of FEH might be similar to that of condyloma acuminatum and oral squamous cell papilloma (2).

Detection of specific HPV genotype by polymerase chain reaction (PCR) is a specific and sensitive method to confirm the diagnosis of FEH (2). Susceptible HPV subtypes of condyloma acuminatum and oral squamous cell papilloma are most frequently 6,11,16 and 18 (3). Human papillomavirus-13 in the children or 32 in adult patients are viral subtypes implicated in most patients with FEH diagnosis (>90\%) (3). When suspicion of condyloma acuminatum or venereal warts is raised, particularly in children, accurate genotyping diagnosis should be mandatory to rule out suspected of sexual abuse.

\section{REFERENCES}

1. Ghalayani P, Tavakoli P, Eftekhari M, Haghighi MA. Oral focal epithelial hyperplasia: Report of three cases. Turk Patoloji Derg. 2015;31:60-3.

2. Said AK, Leao JC, Fedele S, Porter SR. Focal epithelial hyperplasiaan update. J Oral Pathol Med. 2013;42:435-42.

3. Liu N, Li Y, Zhou Y, Zeng X. Focal epithelial hyperplasia (Heck's disease) in two Chinese females. Int J Oral Maxillofac Surg. 2012;41:1001-4.

\section{Gian Paolo BOMBECCARI}

Department of Biomedical, Surgical, and Dental Sciences, Unit of Oral Pathology and Medicine, University of Milan, Via Della Commenda 10, 20122 MILAN, ITALY

E-mail: gpbombeccari@libero.it

Phone: +39-02-503 20242

Gianpaolo GUZZI

Italian Association for Metals and Biocompatibility Research, A.I.R.M.E.B., MILAN, ITALY

Francesco PALLOTTI

Unit of Anatomical Pathology, Fondazione IRCCS Ca' Granda Ospedale Maggiore Policlinico, University of Milan, MILAN, ITALY

Francesco SPADARI

Department of Biomedical, Surgical, and Dental Sciences, Unit of Oral Pathology and Medicine, University of Milan, MILAN, ITALY

Aldo Bruno GIANNİ

Maxillo-Facial and Odontostomatology Unit, Fondazione Cà Granda IRCCS Ospedale Maggiore Policlinico, Department of Biomedical, Surgical and Dental Sciences, University of Milan, MILAN, ITALY 